\title{
DEXTRAN SULFATE STABILIZED SILVER NANOPARTICLE: NEXT GENERATION EFFICIENT THERAPY FOR CANCER
}

\section{SHARMILA CHANDRAN ${ }^{*}$, THILAGAVATHY PONNUSAMYa, DINESH BHEEMAN ${ }^{b}$, RANJITH KUMAR RAJAMANIc, CHANDAR SHEKAR BELLAN ${ }^{*}$}

aDepartment of Physics, PSGR Krishnammal College for Women, Coimbatore 641004, Tamil Nadu. India, biology Division, Department of Applied Sciences, Higher College of Technology, Muscat-133, Sultanate of Oman, 'Department of Biotechnology, Kongunadu Arts and Science College, G. N Mills, Coimbatore 641029, Tamil Nadu, India, dDepartment of Physics, Kongunadu Arts and Science College, G. N Mills, Coimbatore 641029, Tamil Nadu, India

Email: sharmilakshu@gmail.com

Received: 12 Aug 2019, Revised and Accepted: 04 Nov 2019

ABSTRACT

Objective: Synthesize silver nanoparticles using a green synthesis approach and encapsulate silver nanoparticles with a naturally occurring polymer, particularly of an-hydroglucose type, like dextran sulfate sodium salt and to study its anticancer activity.

Methods: Green synthesis approach is been employed in the synthesis of silver nanoparticles using Psidium guajava leaf extract. The nanoparticles were then encapsulated with dextran sulfate biopolymer and the nanoparticles were subjected to different characterization techniques. The structure of the synthesized nanoparticles was analyzed using X-ray diffraction analysis, the presence of different functional groups was analyzed by FTIR studies. Size and morphology of the prepared nanoparticles were investigated using FESEM analysis. Anticancer activity of the synthesized nanoparticles was tested against the MCF-cell line

Results: The XRD analysis shows the crystalline nature of the synthesized nanoparticles. The stretching and vibrating modes of different functional groups were confirmed by FTIR result. The SEM image confirmed the presence of spherical shaped nanoparticles and the TEM image confirmed the average size of the particles to be around $24 \mathrm{~nm}$. The Ag-DS NPs showed $91 \%$ cell inhibition for the concentration of $100 \mu \mathrm{g} / \mathrm{ml}$, indicating the cytotoxicity of the nanoparticles against MCF-7 cell line.

Conclusion: Dextran sulfate stabilized silver nanoparticles show potent anticancer activity against MCF-7 cell line.

Keywords: Silver nanoparticles, Biopolymer, Dextran sulfate, Anticancer activity

(c) 2020 The Authors. Published by Innovare Academic Sciences Pvt Ltd. This is an open-access article under the CC BY license (http://creativecommons.org/licenses/by/4.0/) DOI: http://dx.doi.org/10.22159/ijap.2020v12i1.35327 Journal homepage: https://innovareacademics.in/journals/index.php/ijap

\section{INTRODUCTION}

Nanoparticles are of great scientific interest among the research community because they form an effective bridge between bulk materials and atomic or molecular structures. Metal nanoparticles possess unique properties, for which they are used in many applications like catalysis, sensing and imaging etc., [1-3]. Silver nanoparticle is one of the most vital and fascinating nanomaterials among various metal nanoparticles. The use of silver nanoparticles for different applications depends on various factors including surface chemistry, size, size distribution, shape, particles morphology, particles composition, coating/capping, agglomeration, dissolution rate, particles reactivity in solution, efficiency of ion release and, type of reducing agent [4]. Encapsulating the synthesized nanoparticles in the polymeric matrix which is made from biodegradable and biocompatible polymer can be used for a controlled drug delivery system [5].

Silver nanoparticles tend to adhere to each other to form agglomeration because of Vander Waals forces that act over a short distance. Agglomeration due to Brownian motion is classified as coagulation [6]. To avoid agglomeration, a most suitable dispersing and binder agent dextran sulfate is used. Dextran sulfate is a polymer of an-hydroglucose which are soluble and stable in water. Dextran sulfate contains $17 \%$ sulfur, which is equivalent to 2.3 sulfate groups per glucose residue. Dextran sulfate is a biopolymer having a well-defined structure that differs from a synthetic polymer having more random structure [7]. Silver nanoparticles or silver ions coordinate with carboxyl group and have a physical-steric interaction. Dextran derivative such as carboxymethyl dextran or dextran sulfate contains one or more carboxyl or sulpho groups, therefore allowing conditions for forming complex compounds of different compositions and coordination with silver ions [8].

The aim of the present study is to synthesize silver nanoparticles by green synthesis approach using Psidium guajava leaf extract as a reducing agent and to encapsulate these nanoparticles with the dextran sulfate matrix. The synthesized Ag-DS NPs were subjected to various characterization techniques. Finally, the anticancer activity of the green synthesized Ag-DS NPs were analyzed. In vitro cell line analysis on MCF7 cell line was carried out using MTT assay.

\section{MATERIALS AND METHODS}

\section{Chemicals and reagents}

Silver nitrate (99\% purity) and all other chemicals used in the synthesis of Ag-DS NPs were purchased from Himedia India Private limited, Dextran sulfate was purchased from Sigma Aldrich chemical, India. All the chemicals used were of analytical grade purity. Psidium guajava leaves used were collected from local residents around Coimbatore.

\section{Preparation of leaf extract}

Psidium guajava leaves were collected from the local residents in and around Coimbatore and the plant materials were identified and authenticated by Botanical Survey of India, Coimbatore, TamilNadu (Voucher No: SI/SRC/5/23/2010-11/Tech. 1785). Fresh leaves of Psidium guajava were collected and cut into small pieces. These leaves were washed thoroughly for several times with double distilled water to remove dust and other particles attached to the surface of leaves. Psidium guajava leaf extract was prepared by weighing $20 \mathrm{~g}$ of freshly cut leaves with $200 \mathrm{ml}$ of double-distilled water boiled at $60^{\circ} \mathrm{C}$ in Erlenmeyer flask for $20 \mathrm{~min}$ [9]. The Psidium guajava leaf extract was then filtered through Whatman No.1 filter paper [10]. The filtered was used for the synthesis of nanoparticles in room temperature.

\section{Green synthesis of Ag-DS NPs}

Silver nanoparticles were synthesized by mixing $100 \mathrm{ml}$ of $1 \times 10^{-3} \mathrm{M}$, aqueous silver nitrate with $5 \mathrm{ml}$ of Psidium guajava leaf extract and 
the mixture were stirred vigorously for $20 \mathrm{~min}$ in a magnetic stirrer at room temperature [11]. It was observed that color of the reaction mixture changed from light yellow to reddish-brown that indicating the formation of AgNPs [12].

Initially, 0.005 gms of dextran sulfate was mixed with $5 \mathrm{ml}$ of double-distilled water $(1 \mathrm{mmol})$ and stirred on a magnetic stirrer for $20 \mathrm{~min}$ at room temperature. The green synthesized AgNPs using Psidium guajava leaf extract as a reducing agent was then added with dextran sulfate biopolymer. For each of $10 \mathrm{ml}$ of colloidal green synthesized Ag nanoparticle solution, 2 drops of dextran sulfate were added and stirred on a magnetic stirrer for $1 \mathrm{~h}$ at room temperature. Finally, the synthesized nanoparticles were subjected to various characterization techniques.

\section{Characterization of Ag-DS NPs}

The final products obtained by chemical synthesis and green synthesis were characterized using X-ray Diffractometer (XRD, Bruker D8 Advance, CuK $\alpha(\mathrm{k}=1.540593 \AA$ A), Fourier Transform Infrared Spectroscopy (FTIR, IR-Affinity 1, Shimadzu), Field Emission Scanning Electron Microscope (FESEM, JEOL-JSM-6490LA), Energy Dispersive Spectroscopy (EDS, JEOL-JSM-6490LA), and High resolution Transmission Electron Microscope (HRTEM, JEOL-JEM2100).

\section{In vitro anticancer activity}

The human breast cancer cells (MCF-7) were obtained from National Center for Cell Science (NCCS), Pune and the cells were treated with serial concentration $(12.5,25,50$ and $100 \mu \mathrm{g} / \mathrm{ml})$ of the green synthesized Ag-DS NPs. The plates containing the synthesized nanoparticles were added with $5 \mathrm{mg} / \mathrm{ml}$ in phosphate buffer saline (PBS) solution. The plates were incubated at 370C for $4 \mathrm{~h}$. MTT assay the medium without samples was served as control and triplicate was maintained for all concentrations.

The $\%$ cell inhibition was determined using the following formula.

Mean absorbance of test sample

100- Mean absorbance at control X 100---Eqn. 1.1

A nonlinear regression graph was plotted between \% cell inhibition and Log concentration and IC 50 was determined using GraphPad Prism software.

\section{RESULTS AND DISCUSSION}

\section{$\mathrm{X}$-ray diffraction analysis}

The XRD peaks of the green route synthesized Ag-DS NPs are shown in fig. 1. The XRD spectrum shows the main predominant Braggs diffraction peaks, which are positioned at $2 \theta$ value of $66.3^{\circ}$ corresponding to (220) plane. The orientation plane (200), (104), and (311) was also observed at $2 \theta=45.3^{\circ}, 54.9^{\circ}$, and $78.4^{\circ}$. These planes correspond to facets of metallic silver. Due to the crystal symmetry and relative phase velocity, the common crystal habitat of silver nanoparticles showed a face-centered cubic shape $[13,14]$. These diffraction peaks are consistent with the standard Ag crystals (JCPDS Card No.40783), indicating that the synthesized AgNPs are of crystalline in nature. These results are in good correlation with previously reported results of AgNPs $[15,16]$.

The crystallite size of the green synthesis AgNPs was calculated by the Debye-Scherrer equation, $\mathrm{D}=\mathrm{K} \lambda / \beta \cos \theta$. Where $\mathrm{D}=$ average crystallite size, $\mathrm{K}$-shape factor (0.9), $\lambda$-wavelength of $\mathrm{Cu} \mathrm{K} \alpha$ radiation $(1.541 \AA)$ ), $\beta$-FWHM of refection (in radians) located at $2 \theta$ and $\theta$ angle of reflection (in degrees) was used to relate the crystallite size to the line broadening. The average crystallite size of prepared AgNPs was found to be about $20 \mathrm{~nm}$.

\section{FTIR analysis}

To identify the different functional groups present in the synthesized Ag-DS NPsa FTIR analysis was carried out. Fig. 2 shows the FTIR spectrum of the green synthesized Ag-DS NPs. The broad absorption peak at $3265 \mathrm{~cm}^{-1}$ corresponds to the stretching vibration of the hydrogen bond, which shows the presence of $\mathrm{O}-\mathrm{H}$ stretching of phenol and hydroxyl group. A weak absorption band at $2923 \mathrm{~cm}^{-1}$ might be due to C-C stretching vibration of alkynes. A strong and sharp absorption peak at $1636 \mathrm{~cm}^{-1}$ may be due to primary amide $\mathrm{NH}_{2}$ bending [17]. Medium peak observed at $1451 \mathrm{~cm}^{-}$ ${ }^{1}$ is due to symmetric and asymmetric $\mathrm{C}-\mathrm{H}$ deformation vibration of alkanes group. Medium peak observed at $1518 \mathrm{~cm}^{-1}, 1327 \mathrm{~cm}^{-1}$ and $1242 \mathrm{~cm}^{-1}$ corresponds to $\mathrm{O}-\mathrm{H}$ deformation vibration belonging to alcohol group. Strong peak corresponding to $1022 \mathrm{~cm}^{-1}$ shows C-O stretching vibration of alcohol group. A strong absorption peak found at $667 \mathrm{~cm}^{-1}$ may be due to $\mathrm{C}-\mathrm{H}$ plane deformation vibration of alkyl halides and aromatics group. The observed peaks are consistent with previous reports $[18,19]$.

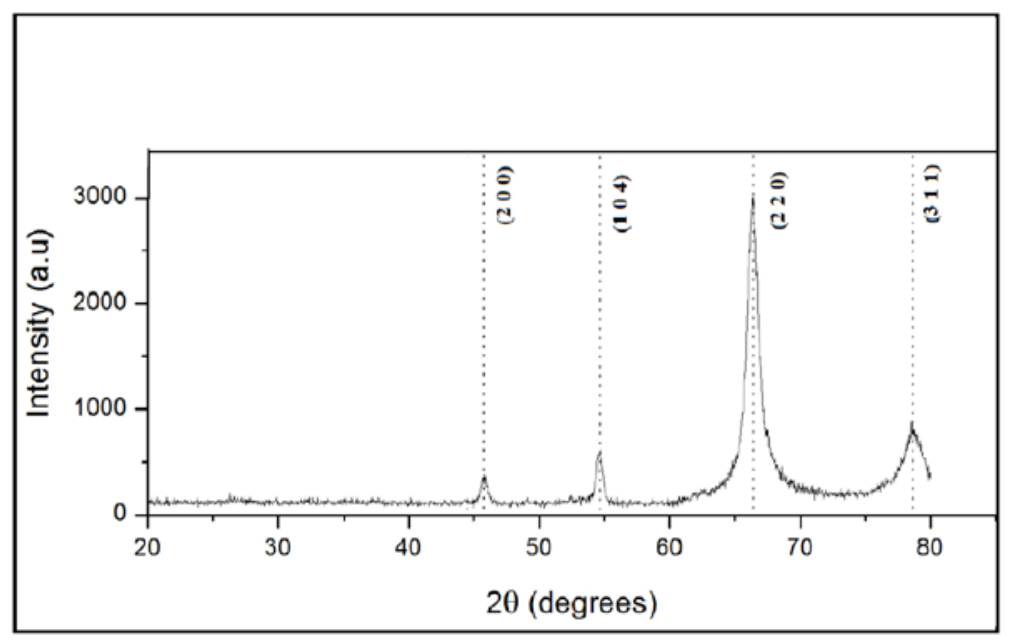

Fig. 1: X-ray diffraction spectrum of Ag-DS NPs

\section{FESEM and EDAX analysis}

Fig. 3 shows the field emission scanning electron microscopy image of Ag-DS NPs. The image of indicates that the nanoparticles are composed of large scale mono-dispersed, spherical-shaped structure.
The dispersive energy spectrum (EDS) was done along with the FESEM analysis. The EDS spectra of the green route prepared Ag-DS NPs is shown in fig. 4. The compositional analysis confirms the presence of silver along with carbon, silicon, sodium, calcium, magnesium, iron, and oxygen elements. The elemental composition 
of the green synthesized silver nanoparticles shows only 39\% of elemental silver, along with all other compounds.

Oxygen was observed with a weight percentage with $16 \%$, carbon with $22 \%$, silicon with $15 \%$, sodium with $1 \%$, calcium with $2 \%$, magnesium with $0.65 \%$, and iron with $1 \%$. All the other elements present in the spectrum ie., carbon, sodium, calcium, magnesium, iron and oxygen, might be contributed due to the plant's profile and dextran sulfate biopolymer. They might have also araised due to the synthesis procedure adopted to prepare nanoparticles. The element silicon might have contributed due to the grid used for the holding sample in the electron microscope apparatus.

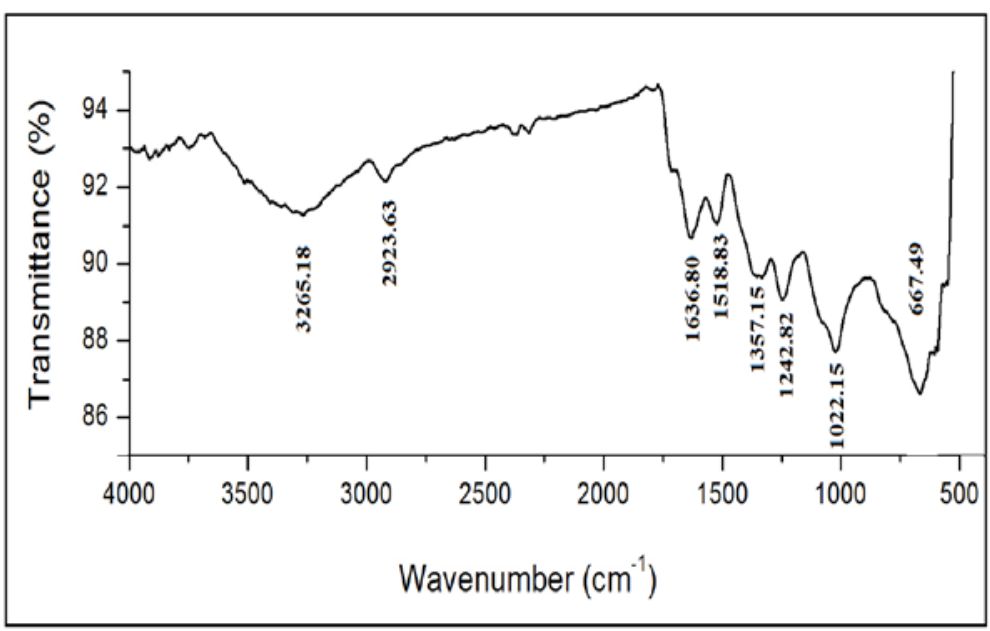

Fig. 2: FTIR spectrum of Ag-DS NPs

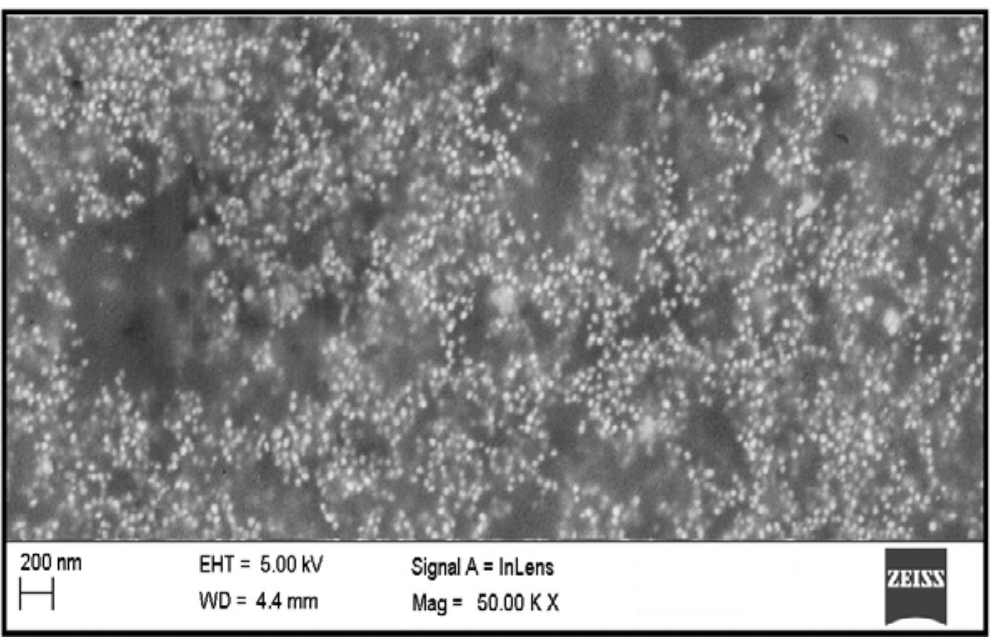

Fig. 3: FESEM micrographic image of Ag-DS NPs

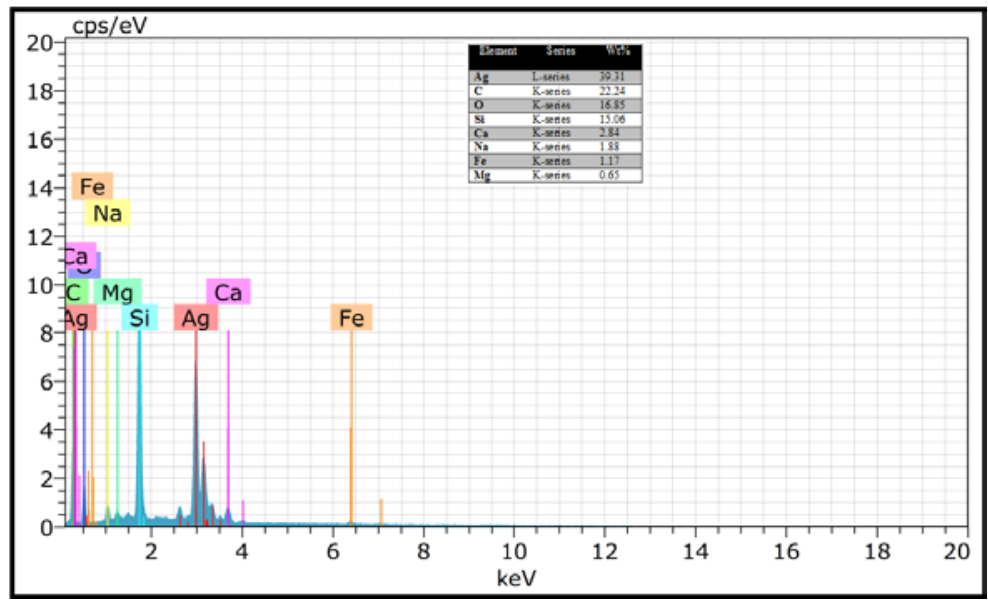

Fig. 4: EDAX analysis of Ag-DS NPs 


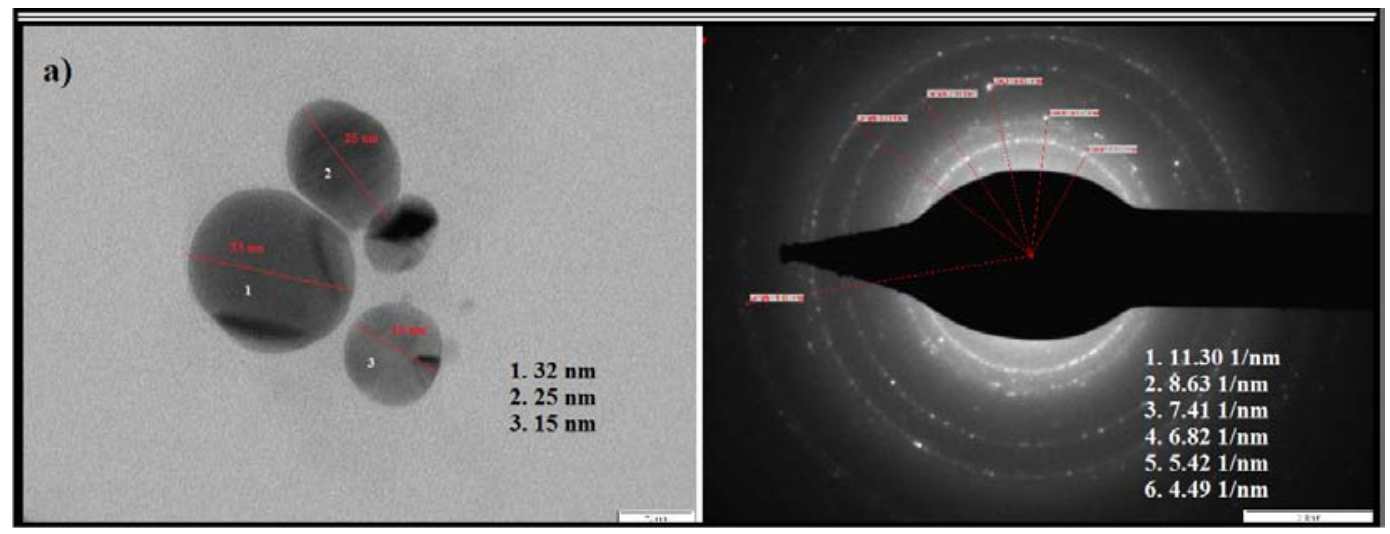

Fig. 5: TEM micrographic image of Ag-DS NPs

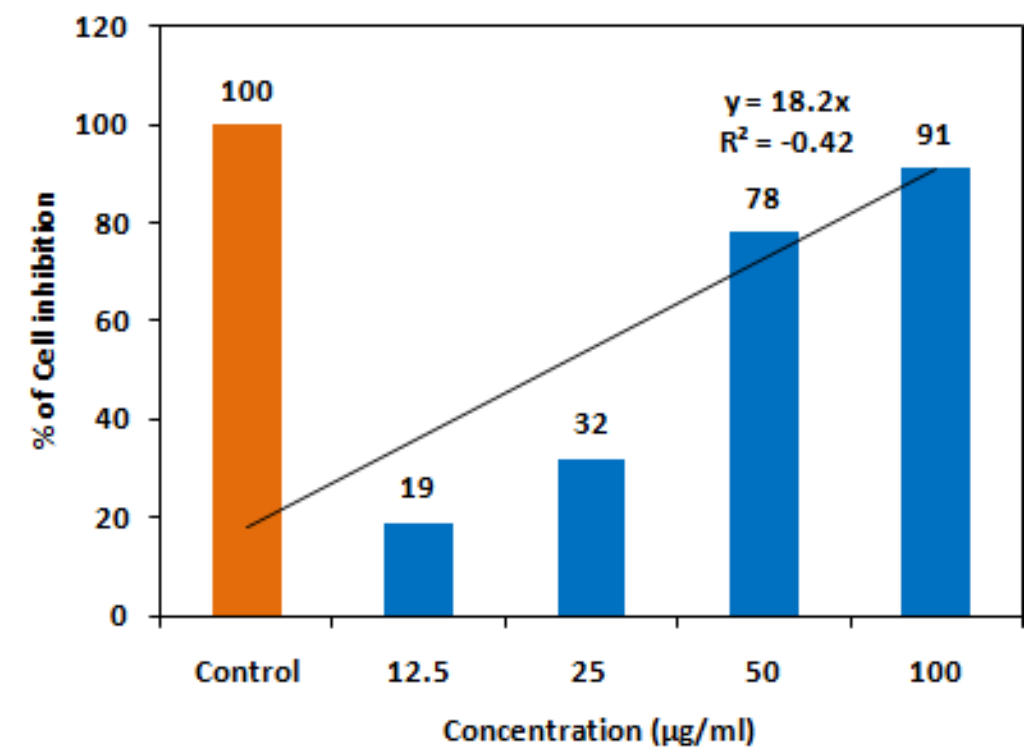

Fig. 6: Anticancer activity of green synthesized Ag-DS NPs on cancer cell line MCF-7

\section{TEM analysis}

Fig. 5 shows the TEM image and SAED pattern of green synthesized Ag-DS NPs. The image shows that the green synthesized Ag-DS NPs are spherical in shape with an average particle size of $24 \mathrm{~nm}$.

\section{Anticancer activity}

Anticancer activity of the synthesized Ag-DS NPs demonstrated significant cytotoxicity against MCF-7 human breast cancer cell lines at different concentrations $(12.5,25,50$ and $100 \mu \mathrm{g} / \mathrm{ml})$. Fig. 6 represents $91 \%$ of cell death, which was observed in the highest concentration of $100 \mu \mathrm{g} / \mathrm{ml} .78 \%$ of cell death was observed for 50 $\mu \mathrm{g} / \mathrm{ml}$ concentration. The IC 50 value of Ag-DS NPs against human breast cancer MCF-7 cells holds around $37.81 \mu \mathrm{g} / \mathrm{ml}$.

\section{CONCLUSION}

Ag-DS NPs were synthesized at room temperature using Psidium guajava leaf extract as a reducing agent. The XRD analysis shows high intense diffraction peaks indicating the crystalline nature of synthesized Ag-DS NPs with face-centered cubic structure. The FTIR spectrum shows weaker to medium bands corresponding to different functional groups, which might have araised due to the characteristics of Psidium guajava plant. A spherical shaped structure with uniform distribution of the grains was observed from the micrograph images. The EDAX spectrum shows different elemental composition peaks related to carbon, silicon, sodium, calcium, magnesium, iron and oxygen which would support the biocompatibility of the green synthesized nanoparticles. Green synthesized Ag-DS NPs have a particles size of about $24 \mathrm{~nm}$. The SAED pattern confirms the crystalline nature of the nanoparticles. The Ag-DS NPs showed 91\% cell inhibition for the concentration of $100 \mu \mathrm{g} / \mathrm{ml}$, indicating the cytotoxicity of the nanoparticles against MCF-7 cell line. Psidium guajava leaf extract might also be responsible for the anticancer activity of green synthesized Ag-DS NPs.

\section{AUTHORS CONTRIBUTIONS}

All the authors have contributed equally.

\section{CONFLICT OF INTERESTS}

\section{Declared none}

\section{REFERENCES}

1. Crooks RM, Zhao M, Sun L, Chechik V, Yeung LK. Dendrimerencapsulated metal nanoparticles: Synthesis, characterization and applications to catalysis. Acc Chem Res 2001;34:181-90.

2. Lee KS, El-Sayed MA. Gold and silver nanoparticles in sensing and imaging: sensitivity of plasmon response to size, shape and metal composition. J Phys Chem B 2006;110:19220-5.

3. Prashant KJ, Huang X, El-Sayed IH, El-Sayed MA. Nobel metal on the nanoscale: Optical and Photothermal properties and some applications in imaging, sensing, biology and medicine. Acc Chem Res 2008;41:1578-86. 
4. Carlson C, Hussain SM, Schrand AM, Braydich Stolle LK, Hess $\mathrm{KL}$, Jones RL, et al. Unique cellular interaction of silver nanoparticles: size-dependent generation of reactive oxygen species. J Phys Chem B 2008;112:13608-19.

5. Divya J, Sneh P, Jainey PJ. Antimicrobial potential of hydrogel incorporated with PLGA nanoparticles of Crossandra Infundibuliformis. Int J Appl Pharm 2019;11:1-5.

6. Maria B. An introduction to nanoparticles and nanotechnology. Morgan Claypool Pub; 2015. p. 1-14.

7. Rankin JC, Jeanes A. Evaluation of the periodate oxidation method for structural analysis of dextrans. J Am Chem Soc 1954:76:4435-41

8. Glisic S, Cakic M, Nikolic G, Danilovic B. Synthesis, characterization and antimicrobial activity of carboxymethy dextran stabilized silver nanoparticles. J Mol Struct 2015; 1084:345-51.

9. Kirthika P, Dheeba B, Sivakumar R, Sheik Abdulla S. Plant mediated synthesis of silver nanoparticles. Int J Pharm Pharm Sci 2014;8:304-10.

10. Sharmila C, Vinuppriya R, Chandran S, Chemmanda J, Chandarshekar B. Biosynthesis of PVA encapsulated silver nanoparticles. J Appl Res Tech 2016;14:319-24.

11. Mubarak Ali D, Thajuddin N, Jeganathan K, Gunasekaran M. Plant extract mediated synthesis of silver and gold nanoparticles and its antibacterial activity against clinically isolated pathogens. Coll Surf B Biointer 2011;85:360-5.
12. Sunitha P, Rajeswari S, Rajiv P, Rajendran V, Seenivasan R. Green synthesis of silver nanoparticles from leaf extract of Aegle marmelos and evaluation of its antibacterial activity. Int J Pharm Pharm Sci 2015;6:169-73.

13. Dipanwita M, Mrinal KB, Biplab B, Joy S, Saswati S, Krishnendu A, et al. In situ synthesis, characterization, and antimicrobial activity of silver nanoparticles using water-soluble polymer. Inc J Appl Polym Sci 2011;122:2189-96.

14. Nguyen TK, Luke AWG. Fictionalization of nanoparticles for biomedical applications. Nano Today 2010;5:213-30.

15. Shipway A, Willner I. Nanoparticles as structural and functional units in surface-confined architectures. Chem Commun 2001;20:2035-45.

16. Antony Lawrence A, Thomas JPJ. Biogenic synthesis of silver nanoparticles using Manilkara hexandra (ROXB.) dubard stem bark extract and its physical, chemical characterization and pharmaceutical evaluation. Int J Appl Pharm 2019;11:79-88.

17. Rajeswari A, Vinoth J. Biogenic potential of stabilized silver nanoparticles using G. Sylvestrae and their biological assays. Int J Appl Pharm 2019;11:130-7.

18. Noorsaiyyidah DS, Nurul ACL, Mohd RJ, Roslina A. FTIR studies on silver-poly (methylmethacrylate) nanocomposites via In-situ polymerization technique. Int J Electrochem Sci 2012;7:5596-603.

19. Awwad AM, Salem NM, Abdeen AO. Biosynthesis of silver nanoparticles using Olea europaea leaves extract and its antibacterial activity. Nanosci Nanotech 2012;2:164-70. 